\title{
KOMBINASI ELEKTROKOAGULAI DENGAN MEDIA CLAY FILTER DALAM MENURUNKAN KADAR FOSFAT $\left(\mathrm{PO}_{4}\right)$ LIMBAH LAUNDRY Ain Khaer ${ }^{1}$ dan Rusli ${ }^{2}$ \\ ${ }^{1.2}$ Poltekkes Kemenkes Makassar \\ keslingrusli@gmail.com
}

\begin{abstract}
Laundry wastewater containing phosphate levels (PO4) will accumulate in the water causing eutrophication of the algae growth explosion resulting in decreased oxygen dissolved in water, so that the water body becomes anoxic, death of aquatic biota and there is a decrease in water quality, so it requires the processing of laundry wastewater before being discharged to environmental media. The purpose of the study was to determine the decrease in phosphate levels (PO4) after going through a combination electrocoagulation treatment process with clay filter media with a time of 90 minutes, 120 minutes and 150 minutes. This type of quantitative research is conducted experimentally with a pre-test post-test design, which is testing by comparing phosphate levels (PO4) before and after treatment. Processing and presenting data in table form. Data were analyzed by Kruskal-Wallis statistical test. The results showed that there was a decrease in phosphate levels (PO4) after the combination of electrocoagulation treatment with clay filter media. At 90 minutes the efficiency decreases $3.49 \mathrm{mg} / \mathrm{I}(90.72 \%)$, the time is $1203.60 \mathrm{mg} / \mathrm{I}(92.49 \%)$ and the time is $1503.51 \mathrm{mg}$ $/ /(94.33 \%)$. And the results of statistical tests showed that the p-value (0.285) $p>\alpha(0.05)$ there was no significant difference in phosphate levels (PO4) between 90 minutes, 120 minutes and 150 minutes. Processing of a combination of electrocoagulation with clay filter media can be used by laundry entrepreneurs to treat their wastewater. As a suggestion to the next researcher, it is better to test other parameters in laundry wastewater using a voltage above 24 volts, adding the number of electrodes and activated charcoal added to the filtration media
\end{abstract}

Keywords: Laundry wastewater, electrocoagulation, clay filter media, treatment time, phosphate content (PO4)

\section{ABSTRAK}

Air limbah laundry mengandung kadar fosfat $\left(\mathrm{PO}_{4}\right)$ akan terakumulasi diperairan menimbulkan eutrofikasi terjadinya ledakan pertumbuhan alga mengakibatkan menurunya oksigen terlarut dalam air, sehingga badan air jadi anoksik, kematian biota perairan dan terjadi penurunan kualitas air, sehingga diperlukan pengolahan air limbah laundry sebelum dibuang ke media lingkungan. Tujuan penelitian adalah mengetahui penurunan kadar fosfat $\left(\mathrm{PO}_{4}\right) \mathrm{Setelah}$ melalui proses perlakuan kombinasi elektrokoagulasi dengan media clay filter dengan waktu 90 menit, 120 menit dan 150 menit. Jenis penelitian yang dilakukan kuantitatif eksprimental dengan rancangan pre-test post-test, yaitu pengujian dengan membandingkan kadar fosfat $\left(\mathrm{PO}_{4}\right)$ sebelum dan setelah perlakuan. Pengolahan dan penyajian data dalam bentuk tabel. Data dianalisis dengan uji statistik kruskal - wallis. Hasil penelitian menunjukkan bahwa terjadi penurunan kadar fosfat $\left(\mathrm{PO}_{4}\right)$ setelah perlakuan kombinasi elektrokoagulasi dengan media clay filter. Waktu 90 menit efesiensi penurunan 3,49 mg/l (90,72\%), waktu $120 \quad 3,60 \mathrm{mg} / \mathrm{l}(92,49 \%)$ dan waktu $1503,51 \mathrm{mg} / \mathrm{l}(94,33 \%)$. Dan hasil uji statistik menunjukkan bahwa nilai $p(0,285) \mathrm{p}>\alpha(0,05)$ maka tidak ada perbedaan yang signifikan penurunan kadar fosfat $\left(\mathrm{PO}_{4}\right)$ antara waktu 90 menit, 120 menit dan 150 menit. Pengolahan kombinasi elektrokoagulasi dengan media clay filter dapat digunakan pengusaha laundry untuk mengolah air limbahnya. Sebagai saran kepada peneliti selanjutnya, sebaiknya menguji parameter lain dalam air limbah laundry dengan menggunakan tegangan diatas 24 volt, menambahkan jumlah elektroda dan arang aktif ditambahkan pada media filtrasi

Kata Kunci : Air Limbah laundry, elektrokoagulasi, media clay filter, waktu perlakuan, kadar fosfat $\left(\mathrm{PO}_{4}\right)$

\section{PENDAHULUAN}

Usaha laundry setiap harinya memerlukan rata-rata air bersih 15 liter dalam memproses $1 \mathrm{~kg}$ pakaian, menghasilkan 400 $\mathrm{m}^{3} \quad$ limbah cair per hari mengandung dari penggunaan deterjen (Subriyer, 2013). Kadar fosfat $\left(\mathrm{PO}_{4}\right)$ apabila melebihi nialai ambang batas akan mempengaruhi keseimbangan ekosistem perairan, menyebabkan eutrofikasi yaitu pencemaran air disebabkan nutrien berlebihan. ( Manihar, 2012).

Berdasarkan observasi dan wawancara dengan pemilik salah satu usaha laundry di Kelurahan Banta- Bantaeng Kota Makassar di dapatkan informasi usaha tersebut memiliki 10 unit mesin cuci dengan kapasitas $2 \mathrm{~kg}, 8$ $\mathrm{kg}, 12 \mathrm{~kg}$ dan $17 \mathrm{~kg}$. Setiap harinya memproses $70 \mathrm{~kg}$ pakaian dan membutuhkan air bersih $1,05 \mathrm{~m}^{3} /$ hari . Air limbah dari proses pencucian langsung di buang ke drasnaise tanpa melalui proses pengolahan. Hasil uji pendahuluan kadar fosfat $\left(\mathrm{PO}_{4}\right)$ sampel air laundry tersebut $4,640 \mathrm{mg} / \mathrm{l}$ kadar tersebut telah melebihi nilai ambang batas berdasarkan Peraturan Menteri Lingkungan Hidup. No.5. Tahun 2014. Nilai ambang batas kadar fosfat $\left(\mathrm{PO}_{4}\right) 2 \mathrm{mg} / \mathrm{l}$. maka diperlukan upaya pengolahan terlebih dahulu sebelum dibuang ke lingkungan.

Elektrokoagulasi merupakan suatu proses koagulasi kontinyu menggunakan arus listrik searah melalui peristiwa elektrokimia, yaitu gejala dekomposisi elektrolit, yang salah satu elektrodanya terbuat dari logam. Reaksi kimia yang terjadi pada elektrokoagulasi yaitu reaksi reduksi dan oksidasi, sebagai akibat adanya arus listrik searah (Atikah, 2016). Media clay filter (filter tanah liat ) mempunyai 
kemanpuan adsorbsi fosfat $\left(\mathrm{PO}_{4}\right)$ karena komponen pembentuk media tanah liat modifikasi yaitu, tanah liat, kapur dan serbuk kayu mempunyai konstribusi masing masing dalam menyisihkan kadar fosfat $\left(\mathrm{PO}_{4}\right)$. M. Rizki, ( 2015)

\section{BAHAN DAN METODE}

\section{Lokasi Penelitian}

Penelitian di laksanakan di Laboratorium Terapan Jurusan Kesehatan Lingkungan Poltekkes Kemenkes Makassar dan Pemeriksaan sampel penelitian dilakukan di Balai Laboratorium Kesehatan Lingkungan dan Pengendalian Penyakit (BTKLP) Kota Makassar sedangkan sampel air limbah berasal dari usaha laundry di Kelurahan Banta- Bantaeng Kota Makassar

\section{Desain dan Variabel Penelitian}

Jenis penelitian yang dilakukan kuantitatif eksprimental dengan desain pre-test post-test, yaitu pengujian dengan membandingkan kadar fosfat $\left(\mathrm{PO}_{4}\right)$ sebelum dan setelah perlakuan

Variabel dalam penelitian ini adalah kombinasi elektrokoagulasi dengan media clay filter dengan waktu perlakuan 90 menit, 120 menit dan 150 menit dalam menurunkan kadar fosfat $\left(\mathrm{PO}_{4}\right)$ limbah cair laundry

\section{Populasi dan Sampel}

Populasi dalam penelitian ini jumlah air limbah yang berasal dari proses pencucian pakaian usaha laundry yang dinyatakan dalam liter.

Sampel dalam penelitian ini sebagian limbah cair usaha laundry yang diambil langsung dari outlet mesin cuci sesaat setelah proses pencucian.

\section{Pengumpulan Data}

a. Data perimer

Data perimer diperoleh berdasarkan hasil pemeriksaan laboratorium kadar fosfat $\left(\mathrm{PO}_{4}\right)$ sebelum dan setelah perlakuan

b.Data sekunder

Data Sekunder diperoleh dari berbagai referensi baik artikel-artikel, jurnal, buku dan literatur yang lain dianggap dapat mendukung teori, serta memiliki keterkaitan dengan penelitian ini

\section{Analisa Data}

Data yang telah diolah dianalisa dengan uji statistik Non Parametrik Kruskal- Wallis dengan menggunakan
program komputer SPSS untuk mengetahui besarnya perbedaan penurunan Kadar fosfat $\left(\mathrm{PO}_{4}\right)$ setelah dilakukan perlakuan dengan menggunakan kombinasi elektrokoagulasi dengan media clay filter

\section{HASIL}

Berdasarkan hasil pemeriksaan di laboratorium kadar fosfat $\left(\mathrm{PO}_{4}\right)$ air limbah usaha laundry sebelum dan setelah perlakuan dengan kombinasi elektrokoagulasi media clay filter, dapat dilihat pada tabel di bawah ini :

Berdaskan tabel 5.1 hasil pemeriksaan diatas menunjukkan kadar awal fosfat $\left(\mathrm{PO}_{4}\right)$ sebesar 3,85 $\mathrm{mg} / \mathrm{l}$, setelah di lakukan perlakuan selama 90 menit terjadi penurunan rata rata kadar fosfat $\left(\mathrm{PO}_{4}\right)$ dimana total penurunan tiga kali pengulangan sebesar $3,49 \mathrm{mg} / \mathrm{l}$, dengan persentase penurunan sebesar $90,72 \%$

Hasil Pemeriksaan Kadar Fosfat $\left(\mathrm{PO}_{4}\right)$ Air Limbah Laundry Sebelum dan Setelah Perlakuan Menggunakan Kombinasi

Elektrokoagulasi dengan media Clay Filter. Waktu kontak 90 menit

\begin{tabular}{|c|c|c|c|c|c|c|}
\hline \multirow[b]{2}{*}{$\begin{array}{l}N \\
0\end{array}$} & \multirow[b]{2}{*}{$\begin{array}{l}\text { Pemeri } \\
\text { ksaan }\end{array}$} & \multicolumn{5}{|c|}{ Kadar Fosfat $\left(\mathrm{PO}_{4}\right)$} \\
\hline & & $\begin{array}{l}\text { Kontrol } \\
\text { (mg/L) }\end{array}$ & $\begin{array}{l}\text { Seb } \\
\text { elum } \\
\text { (mg/ } \\
\text { L) }\end{array}$ & $\begin{array}{l}\text { Ses } \\
\text { udah } \\
\text { (mg/ } \\
\text { L) }\end{array}$ & $\begin{array}{l}\text { Kadar } \\
(\mathrm{mg} / \mathrm{L})\end{array}$ & $\begin{array}{l}\text { Perse } \\
\text { ntase } \\
(\%)\end{array}$ \\
\hline 1 & $\begin{array}{l}\text { Replik } \\
\text { asi I }\end{array}$ & 3,84 & 3,85 & 0,37 & 3,48 & 90,31 \\
\hline 2 & $\begin{array}{l}\text { Replik } \\
\text { asi II }\end{array}$ & 3,84 & 3,85 & 0,35 & 3,6 & 90,86 \\
\hline 3 & $\begin{array}{l}\text { Replik } \\
\text { asi III }\end{array}$ & 3,84 & 3,85 & 0,34 & 3,67 & 90,99 \\
\hline \multicolumn{2}{|c|}{ Rata - Rata } & 3,84 & 3,85 & 0,36 & 3,49 & 90,72 \\
\hline
\end{tabular}


Hasil Pemeriksaan Kadar Fosfat $\left(\mathrm{PO}_{4}\right)$ Air Limbah Laundry Sebelum dan Setelah Perlakuan

Menggunakan Kombinasi Elektrokoagulasi dengan media Clay Filter.Waktu kontak 120 menit Tahun 2018

\begin{tabular}{|c|c|c|c|c|c|c|}
\hline \multirow[b]{2}{*}{ No } & \multirow{2}{*}{$\begin{array}{l}\text { Peme } \\
\text { riksaa } \\
\text { n }\end{array}$} & \multicolumn{3}{|c|}{ Kadar Fosfat $\left(\mathrm{PO}_{4}\right)$} & \multicolumn{2}{|c|}{ Penurunan } \\
\hline & & $\begin{array}{l}\text { Kontr } \\
\text { ol } \\
\text { (mg/ } \\
\text { L) }\end{array}$ & $\begin{array}{l}\text { Sebel } \\
\text { um } \\
\text { (mg/L) }\end{array}$ & $\begin{array}{l}\text { Sesud } \\
\text { ah } \\
\text { (mg/L) }\end{array}$ & $\begin{array}{l}\text { Kad } \\
\text { ar } \\
\text { (mg/ } \\
\text { L) }\end{array}$ & $\begin{array}{l}\text { Perse } \\
\text { ntase } \\
(\%)\end{array}$ \\
\hline 1 & $\begin{array}{l}\text { Replik } \\
\text { asi I }\end{array}$ & 3,75 & 3,89 & 0,3 & 3,58 & 92,26 \\
\hline 2 & $\begin{array}{l}\text { Replik } \\
\text { asi II }\end{array}$ & 3,75 & 3,89 & 0,29 & 3,59 & 92,42 \\
\hline 3 & $\begin{array}{l}\text { Replik } \\
\text { asi III }\end{array}$ & 3,75 & 3,89 & 0,28 & 3,61 & 92,8 \\
\hline \multicolumn{2}{|c|}{ Rata - Rata } & 3,84 & 3,89 & 0,29 & 3,6 & 92,49 \\
\hline
\end{tabular}

Berdaskan tabel 5.2 hasil pemeriksaan diatas menunjukkan kadar awal fosfat $\left(\mathrm{PO}_{4}\right)$ sebesar $3,89 \mathrm{mg} / \mathrm{l}$, setelah di lakukan perlakuan selama 120 menit terjadi penurunan kadar fosfat $\left(\mathrm{PO}_{4}\right)$ dimana total penurunan dari tiga kali pengulangan sebesar 3,60 $\mathrm{mg} / \mathrm{l}$, dengan persentase penurunan sebesar $92,49 \%$

Tabel 5.3

Hasil Pemeriksaan Kadar Fosfat (PO4) Air Limbah Laundry Sebelum dan Setelah Perlakuan

Menggunakan Kombinasi Elektrokoagulasi dengan media Clay Filter.Waktu kontak 150 menit Tahun 2018

\begin{tabular}{|c|c|c|c|c|c|c|}
\hline \multirow[b]{2}{*}{$\begin{array}{l}\mathbf{N} \\
\mathbf{O}\end{array}$} & \multirow{2}{*}{$\begin{array}{l}\text { Pemer } \\
\text { iksaan }\end{array}$} & \multicolumn{3}{|c|}{$\begin{array}{l}\text { Kadar Fosfat } \\
\text { (PO4) }\end{array}$} & \multicolumn{2}{|c|}{ Penurunan } \\
\hline & & $\begin{array}{l}\text { Kontrol } \\
\text { (mg/L) }\end{array}$ & $\begin{array}{l}\text { Sebel } \\
\text { um } \\
(\mathrm{mg} / \mathrm{L})\end{array}$ & $\begin{array}{l}\text { Sesuda } \\
\mathrm{h} \\
(\mathrm{mg} / \mathrm{L})\end{array}$ & $\begin{array}{l}\mathrm{Kad} \\
\mathrm{ar} \\
(\mathrm{mg} / \\
\mathrm{L})\end{array}$ & $\begin{array}{l}\text { Persent } \\
\text { ase (\%) }\end{array}$ \\
\hline 1 & $\begin{array}{l}\text { Replik } \\
\text { asi I }\end{array}$ & 3,69 & 3,72 & 0,21 & 3,5 & 94,14 \\
\hline 2 & $\begin{array}{l}\text { Replik } \\
\text { asi II }\end{array}$ & 3,69 & 3,72 & 0,21 & 3,5 & 94,33 \\
\hline 3 & $\begin{array}{l}\text { Replik } \\
\text { asi III }\end{array}$ & 3,69 & 3,72 & 0,2 & 3,51 & 94,52 \\
\hline \multicolumn{2}{|c|}{ Rata - Rata } & 3,69 & 3,72 & 0,21 & 3,51 & 94,33 \\
\hline
\end{tabular}

Berdaskan tabel 5.3 hasil pemeriksaan diatas menunjukkan kadar awal fosfat $\left(\mathrm{PO}_{4}\right)$ sebesar $3,72 \mathrm{mg} / \mathrm{l}$, setelah di lakukan perlakuan selama 150 menit terjadi penurunan kadar fosfat $\left(\mathrm{PO}_{4}\right)$ dimana total penurunan dari tiga kali pengulangan sebesar $3,51 \mathrm{mg} / \mathrm{l}$, dengan persentase penurunan sebesar 94,33

Sebagai gambaran kondisi efisiensi dan persentasi penurunan kadar fosfat $\left(\mathrm{PO}_{4}\right)$ air limbah laundry setelah proses perlakuan 90 menit, 120 menit dan 150 menit Kombonasi Elektrokoagulasi Dengan Media clay filter (filter tanah liat)" dapat dilihat berdasarkan pada grafik penurunan kadar fosfat $\left(\mathrm{PO}_{4}\right)$ dan grafik persentase penurunan kadar fosfat $\left(\mathrm{PO}_{4}\right)$ dibawah ini :

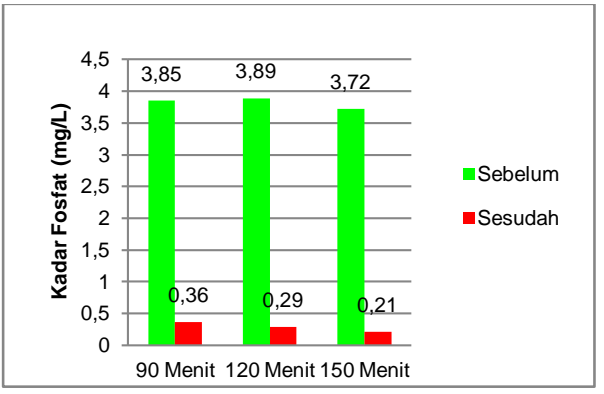

Gambar 5.1. Grafik Hasil Penurunan Kadar Fosfat $\left(\mathrm{PO}_{4}\right)$ Sebelum dan Setelah Perlakuan dengan Waktu Kontak 90 menit, 120 menit dan 150 Menit.

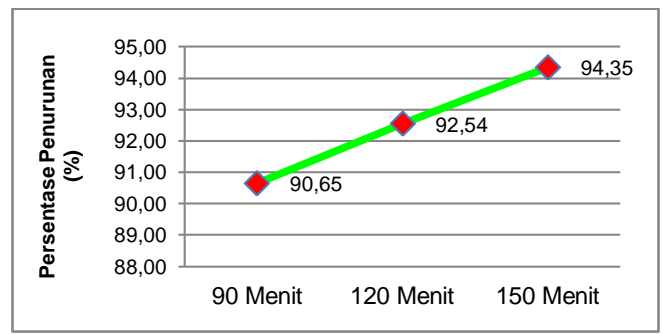

Gambar 5.2. Grafik Hasil Penurunan Kadar Fosfat $\left(\mathrm{PO}_{4}\right)$ Sebelum dan Setelah

Perlakuan dengan Waktu Kontak 90 menit, 120 menit dan 150 Menit.

\section{PEMBAHASAN}

Proses kombinasi elektrokoagulasi, media clay filter dalam penelitian ini efektif menurunkan kadar fosfat $\left(\mathrm{PO}_{4}\right)$. Metode elektrokoagulasi dilakukan secara elektrokimia dengan menggunakan arus listrik searah (DC) 24 volt dengan empat buah elektroda aluminium akan menghasilkan Aluminium Hidroksida $\mathrm{Al}(\mathrm{OH})_{3}$ dari proses reduksi dan oksidasi. Aluminium Hidroksida Al $(\mathrm{OH})_{3}$ bermuatan kation berfungsi sebagai koagulan akan mengikat polutan fosfat $\left(\mathrm{PO}_{4}\right)$ yang bermutan anion, setelah terjadi proses pengikatan terjadi proses flokulasi penggabungan polutan fosfat $\left(\mathrm{PO}_{4}\right)$ menjadi partikel yang lebih besar sehingga mudah untuk diendapkan maupun dipisahkan dengan filtrasi. Sedangkan media clay filter berfungsi sebagai filtrasi dan adsorpsi polutan fosfat $\left(\mathrm{PO}_{4}\right)$ yang belum dapat mengendap maupun terikat pada proses elektrokoagulsi. Sejalan yang dikemukakan Ronny, (2015), filtrasi adalah proses penyaringan untuk menghilangkan zat padat tersuspensi dari air melalui media berfori. Zat padat tersuspensi 
dihilangkan pada waktu air melalui suatu lapisan materi berbentuk butiran yang disebut media filter.

Berdasarkan hasil pengamatan pada saat penelitian dimana pada proses elekektrokoagulasi dimana elektroda aluminium yang berfungsi sebagai kutub negatif (katoda) telah mengalami proses reduksi dan menghasilkan gas $\mathrm{H}_{2}$ dan $\mathrm{OH}^{-}$di tandai terbentuknya gelembung- gelembung gas $\left(\mathrm{H}_{2}\right)$ di atas permukaan air limbah limbah laundry, sedangkan elektroda aluminium yang berfungsi sebagai kutup positif (anoda) mengalami proses oksidasi yaitu pelepasan ion aluminium yang bersifat kation $\mathrm{Al}^{3+}$. Kation $\mathrm{Al}^{3+}$ akan berikatan dengan $\mathrm{OH}^{-}$yang terbentuk dari proses reduksi akan saling berikatan sehingga terbentuk Aluminium Hidroksida $\mathrm{Al}(\mathrm{OH})_{3}$. Terbentuknya $\mathrm{Al}(\mathrm{OH})_{3}$ dari proses reduksi dan oksidasi berfungsi sebagai bahan koagulan akan mengikat polutan fosfat $\left(\mathrm{PO}_{4}\right)$, persamaan reaksi antara ion aluminium dan Fosfat $\left(\mathrm{PO}_{4}\right)$ adalah sebagai berikut: $\mathrm{Al}(\mathrm{OH})_{3}+\mathrm{AlPO}_{4}$

$$
\mathrm{AlPO}_{4} \text { ( endapan) }
$$

Hasil ikatan ion $\mathrm{Al}^{3+}$ dengan Fosfat $\left(\mathrm{PO}_{4}\right)$ pada air limbah laundry akan membentuk flok akan terdorong ke permukaan air limbah oleh gas $\mathrm{H}_{2}$ yang terbentuk dari reaksi reduksi pada elektroda negatif (anoda). Flok -flok tersebut saling bertemu dan bergabung membentuk flok yang lebih besar selama proses elektrokoagulasi sedang berlangsung, sejalan yang dikemukakan Idaman Said, (2017) gumpalan yang terbentuk pada proses koagulasi masih berukuran kecil dengan adanya proses sidementasi gumpalan-gumpalan kecil akan bergabung menjadi gumpalan yang lebih besar dalam proses flokulasi sehingga beratnya akan bertambah, karena gaya beratnya gumpalangumpalan tersebut akan bergerak ke bawah dan mengendap pada bagian dasar bak sidementasi

Komponen pembentuk media clay filter yaitu tanah liat, kapur dan serbuk kayu mempunyai konstribusi masing-masing dalam menyisihkan kadar Fosfat $\left(\mathrm{PO}_{4}\right)$ air limbah laundry. Tanah dan kapur merupakan dua komponen yang secara langsung yang memiliki reaksi langsung dengan fosfat $\left(\mathrm{PO}_{4}\right)$, sedangkan serbuk kayu hanya memperluas permukaan reaksinya. Imroatul Ngulya, (2016)

Tanah liat memiliki kemampuanya melakukan pertukaran ion yang terjadi akibat kation tertarik pada tanah liat yang bermuatan negatif sehingga anion di tolak dari lapisan yang terbentuk pada permukan media tanah liat, selain itu pertukaran anion juga bisa terjadi ketika sejumlah anion yang terserap pada tepi-tepi media, sehingga ion fosfat $\left(\mathrm{PO}_{4}\right)$ akan teradsorpsi dan akan terikat pada permukaan positif dan tepi - tepi mineral media filter tanah liat dengan persamaan reaksi :

$$
\begin{aligned}
& \text { Al- } \mathrm{OH} \text { ( tanah liat) }+\mathrm{H}_{2} \mathrm{PO}_{4}^{-} \quad \mathrm{Al}_{2} \\
& \mathrm{PO}_{4}+\mathrm{OH}^{-}
\end{aligned}
$$

Reaksi tersebut akan menghasilkan ikatan yang sangat kuat antara ion fosfat $\left(\mathrm{PO}_{4}\right)$ dengan $\mathrm{Al}(\mathrm{OH})$ ion tanah liat.

Komponen kapur $\left(\mathrm{CaCO}_{3}\right)$ akan mempengaruhi adanya reaksi elektrostatik antara mineral $\mathrm{Ca}$ yang berada dalam tanah dengan senyawa fosfat $\left(\mathrm{PO}_{4}\right)$, hal ini di karenakan kapur $\left(\mathrm{CaCO}_{3}\right)$ yang di tambahkan akan bereaksi menjadi kalsium karbonat dan selanjutnya $\mathrm{Ca}^{2+}$ tersebut akan ditukarkan dengan $\mathrm{Al}^{3+}$ yang berada di tanah sehingga tanah bermuatan $\mathrm{Ca}$. Persamaan reaksinya seperti di bawah ini :

$\mathrm{CaCO}_{3}+\mathrm{H}_{2} \mathrm{CO}_{3} \longrightarrow \mathrm{Ca}\left(\mathrm{HCO}_{3}\right)_{2}$ $3 / 2 \mathrm{Ca}\left(\mathrm{HCO}_{3}\right)_{2}$ tanah $-\mathrm{Al} \rightarrow \mathrm{Ca}(3 / 2)-$ tanah $+\mathrm{Al}(\mathrm{OH})_{3}+3 \mathrm{CO}_{3}$

\section{KESIMPULAN DAN SARAN Kesimpulan}

Sebagaimana tujuan dari penelitian ini yakni untuk mengetahui kemampuan kombinasi elektrokoagulasi dengan media calay filter dalam menurunkan kadar fosfat $\left(\mathrm{PO}_{4}\right)$ air limbah laundry waktu kontak 90 menit, 120 menit dan 150 menit, maka dapat ditarik kesimpulan penelitian sebagai berikut ;

1. Kombinasi elektrokoagulasi dengan media clay filter mampu menurunkan kadar fosfat $\left(\mathrm{PO}_{4}\right)$ limbah laundry waktu perlakuan 90 menit rata-rata penurunan $3,49 \mathrm{mg} / \mathrm{l}$ dengan persentase penurunan $90,72 \%$

2. Kombinasi elektrokoagulasi dengan media clay filter mampu menurunkan kadar fosfat $\left(\mathrm{PO}_{4}\right)$ limbah laundry waktu perlakuan 120 menit rata rata penurunan $3,60 \mathrm{mg} / \mathrm{l}$ dengan persentase penurunan $92,49 \%$.

3. Kombinasi elektrokoagulasi dengan media clay filter mampu menurunkan kadar fosfat $\left(\mathrm{PO}_{4}\right)$ limbah laundry waktu perlakuan 150 menit rata-rata penurunan $3,51 \mathrm{mg} / \mathrm{l}$ dengan persentase penurunan $94,33 \%$. 


\section{Saran}

1. Bagi peneliti yang ingin melanjutkan penelitian ini, dapat melakukan penelitian menggunakan tegangan diatas 24 volt, menambahkan jumlah elektroda dan arang aktif ditambahkan pada media filtrasi dengan parameter yang berbeda pada limbah laundry

2. Bagi pengusaha laundry, bentuk pengolahan ini merupakan salah satu pilihan yang dapat digunakan untuk mengolah air limbah yang di hasilkan sebelum di buang ke lingkungan

3. Kepada pemerintah setempat lebih tegas terhadap industri laundry yang tidak memiliki sarana pengolahan air limbah

\section{DAFTAR PUSTAKA}

Atika. 2016. Penurunan Kadar Fenol Dalam Limbah Cair Industri Tenun Sonket Dengen Proses Elktrokogulasi. PNSD Jurnal Dosen Studi Teknik Kimia. 1 (2) : 6-15. (Online) http:// www. univpgri- palembang. ac.id (Diakses pada tanggal 10 Desember 2017)

Imroatul Ngulya. 2016. Komparasi Penurunan Kadar Fosfat Dengan Media Adsorben Arang Sekam Padi Dan Tanah Lempung Modifikasi Pada Air Limbah Industri Loundry. KTI Jurusan Kesehatan Lingkungan. Purwokerto : Poli Teknik Kesehatan Semarang. (Online) http:// diplomaiii kesehatan lingkungan blogspot. com ( Diakses pada tanggal 23 Desember 2017)

Kemen LH. 2014. Permen LH No. 5 Tahun 2014Tentang Baku Mutu Air Limbah. Jakarta : Kementerian Lingkungan Hidup.

M. Rizki.J. Balfas. 2015. Penurunan Senyawa Fosfat Pada Limbah Greywater Melalui Dua Macam Media Adsorpsi. Skripsi Program Studi Teknik Lingkungan. Makassar : Universitas Hasanuddin. (Online) http://repository.unhas.ac.id ( Diakses pada tanggal 17 Desember 2017)

Manihar Situmorang. 2012. Kimia Lingkungan. Depok : Raja Grafindo Persada

Nusa Idaman Said, M. Eng. 2017. Teknologi Pengolahan Air Limbah. Suabaya : Erlangga

Puji Lestari, Chairul Amri, Sigid Sudaryanto. 2017 Efektivitas Jumlah Pasangan Elektroda Aluminium Proses Elektrokoagulasi Terhadap Penurunan Kadar Fosfat Limbah Laundry. Jurnal Sanitasi Kesehatan Lingkungan. 9 (1) : 38- 50. (Online) http://eprints. poltekkesjogja.ac.id (Diakses pada tanggal 23 Desember 2017)

Subriyer Nasir, Teguh Budi.SA, Idha Silviaty. 2013. Aplikasi Filter Keramik Berbasis Tanah Liat Alam Dan Zeolit Pada Pengolahan Air Limbah Laundry. Jurnal Bumi Lestari. 13 (1) : 45-51. (Online) https://ojs.unud.ac.id (Diakses pada tanggal 1 Januari 2018) 